Check for updates

Cite this: RSC Adv., 2019, 9, 34486

\title{
Effect of volatile solvent and evaporation time on formation and performance of PVC/PVC-g-PEGMA blended membranes
}

\author{
Qidong Wu, ${ }^{a}$ Wancen Xie, ${ }^{a}$ Haibo Wu, ${ }^{a}$ Liang Wang, (D) *b Songmiao Liang, ${ }^{c}$ \\ Haiqing Chang ${ }^{a}$ and Baicang Liu (D) *a
}

In order to further improve the performances of fabricated PVC/PVC-graft-poly(ethylene glycol) methyl ether methacrylate (PVC/PVC-g-PEGMA) blended membranes, we investigated the inner connections between affecting parameters during preparation and membrane performances. Two parameters including the composition of casting solutions and the solvent evaporation time were selected. In this study, PVC/PVC-g-PEGMA blended membranes were prepared by non-solvent induced phase separation (NIPS) using 1-methyl-2-pyrrolidinone (NMP) and tetrahydrofuran (THF) as mixing solvents. We found that (1) the membrane morphologies like surface pore size and porosity decreased as the ratio of THF to NMP increased, which resulted in the decrease in pure water flux and the increase of sodium alginate (SA) rejection ratio; (2) the presence of THF in the casting solution could significantly lower the membrane surface roughness compared to only using NMP as a solvent; (3) solvent evaporation for an appropriate time increased the hydrophilicity of the membrane. Among these findings, we achieved a membrane exhibiting the highest flux recovery ratio of $98.65 \pm 0.85 \%$ with a mixing ratio of $1: 9$ (THF : NMP) at $60 \mathrm{~s}$ of evaporation time. High pollutant rejection and high flux recovery ratio were achieved. This study provides more insight into the PVC/PVC-g-PEGMA membrane and a more flexible approach to the application of PVC membranes.

Received 16th July 2019

Accepted 21st October 2019

DOI: $10.1039 / c 9 r a 05454 \mathrm{e}$

rsc.li/rsc-advances

\section{Introduction}

Among the common polymers used to fabricate ultrafiltration membranes, poly(vinyl chloride) (PVC) has received attention owing to its good stiffness, high resistance to bases and acids, and low cost. ${ }^{1}$ However, PVC membranes exhibit poor antifouling properties due to their hydrophobicity. ${ }^{2}$ Blending modifications by blending PVC with an amphiphilic copolymer to enhance the antifouling properties of PVC membranes have been reported..$^{3-7}$ Polymeric membranes can be fabricated via several routes and immersion precipitation (immersion in a non-solvent bath) is the most commonly chosen technique. ${ }^{8}$ The final membrane morphologies and performances depend on many experimental parameters, including compositions of the casting solution (like polymer concentration, type of solvent and non-solvent, cosolvent/solvent ratio), the solvent evaporation time before immersion in a coagulation bath, and the composition and

\footnotetext{
${ }^{a}$ Key Laboratory of Deep Earth Science and Engineering (Ministry of Education), Institute of New Energy and Low-Carbon Technology, Institute for Disaster Management and Reconstruction, College of Architecture and Environment, Sichuan University, Chengdu, Sichuan 610207, PR China. E-mail: bcliu@scu.edu.cn ${ }^{b}$ State Key Laboratory of Separation Membranes and Membrane Processes, Tianjin Polytechnic University, Tianjin 300387, China. E-mail: mashi7822@163.com ${ }^{c}$ Vontron Technology Co., Ltd., Guiyang, Guizhou 550018, PR China
}

temperature of the coagulation bath. ${ }^{8-10}$ Solvents such as $\mathrm{N}$ methyl-2-pyrrolidone (NMP) and N,N-dimethylacetamide (DMAc) were separately used to prepare PVC membranes via the phase inversion method. ${ }^{\mathbf{1 1}-13}$ Roy et al. ${ }^{12}$ investigated the effects of molecular weight of additive and solvents (NMP and DMAc) on the performance of PVC-based asymmetric membranes. They found that compared with DMAc, NMP exhibited better interaction with PVC and the membranes prepared using NMP as solvent showed better thermal stability, antifouling properties and mechanical strength.

A volatile solvent like 1,4-dioxane, acetone and tetrahydrofuran (THF) is often chosen as a co-solvent. ${ }^{10}$ We selected THF based on the following reasons. Firstly, we compared the properties, cost, and environmental impact of the three common volatile solvents. Secondly, THF is a common solvent used for membrane synthesis. ${ }^{\mathbf{1 0 1 4 - 1 7}}$ Thirdly, during the evaporation before immersion in coagulation bath, THF evaporates fast, which leads to membranes with a tight active layer. ${ }^{15,17}$ The number of macrovoids underneath the top layer decreased as the evaporation time increased before immersion in coagulation bath. ${ }^{9}$ Especially, when block copolymers are used to prepare membranes via immersion precipitation, the amount of THF and the evaporation time before precipitation are critical parameters for the formation of self-assemble and ordered structure on the skin layer (Table 1). ${ }^{\mathbf{1 6 , 1 7}}$ 
Table 1 The parameters of the three common volatile solvents ${ }^{a}$

\begin{tabular}{llll}
\hline Solvents & 1,4 -Dioxane & THF & Acetone \\
Vapor pressure $(\mathrm{hPa})$ at $2{ }^{\circ} \mathrm{C}$ & 36 & 217.3 & 245.3 \\
Boiling point $\left({ }^{\circ} \mathrm{C}\right)$ & 100 & 66 & 56 \\
Flashing point $\left({ }^{\circ} \mathrm{C}\right)$ & 12 & -17 & -17 \\
Partition coefficient $\left(\log P_{\mathrm{o} / \mathrm{w}}\right)$ & -0.27 & 0.46 & -0.24 \\
$\Delta \delta_{\mathrm{P} / \mathrm{S}}\left(\mathrm{MPa}^{1 / 2}\right)$ & 6.5 & 7.6 & 7 \\
$\Delta \delta_{\mathrm{S} / \mathrm{NS}}\left(\mathrm{MPa}^{1 / 2}\right)$ & 27.4 & 28.4 & 27.9 \\
Price $(500 \mathrm{ml}, \mathrm{AR}, \mathrm{CNY})$ & 1623.84 & 678.66 & 554.71 \\
Hazards & $\mathrm{H} 225, \mathrm{H} 303, \mathrm{H} 319, \mathrm{H} 333, \mathrm{H} 335, \mathrm{H} 413, \mathrm{H} 351$ H225, H302, H313, H316, H318, H335, H336 & $\mathrm{H} 225, \mathrm{H} 319, \mathrm{H} 336$
\end{tabular}

${ }^{a} \Delta \delta_{\mathrm{P} / \mathrm{S}}-$ polymer/solvent solubility parameter. $\Delta \delta_{\mathrm{S} / \mathrm{NS}}-$ solvent/non-solvent solubility parameter, non-solvent: water. All information of the hazards of the solvents is according to Regulation (EC) no. 1272/2008.

In our previous work, ${ }^{18}$ we synthesized the amphiphilic copolymer PVC-g-PEGMA and investigated the effect of the dosage of PVC-g-PEGMA on PVC/PVC- $g$-PEGMA blended membrane properties. We found that PVC-g-PEGMA as an additive could enhance the antifouling properties and pure water flux of PVC ultrafiltration membranes. Especially, when the dosage of PVC-g-PEGMA was $10 \mathrm{wt} \%$, PVC/PVC- $g$-PEGMA blended membrane exhibited the best comprehensive performance. However, DMAc as the solvent of the membrane casting solutions resulted in large macrovoids at the bottom layer of the membrane. Then Xie et al. used the green solvent dimethyl sulfoxide (DMSO) and traditional solvents as mixing solvents to prepared PVC/PVC- $g$-PEGMA blended membranes, and the blended membrane showed high permeability and rejection. ${ }^{19}$

In this work, we chose NMP (a solvent with stronger interaction with PVC but with weaker relative affinity with water compared to DMAc) as solvent and volatile THF as co-solvent according to Hansen solubility parameter and investigated the effects of the addition of THF and evaporation time on the performance of PVC/PVC- $g$-PEGMA blended membranes. We aimed to decrease the macrovoids at the bottom layer of the membrane and further improve the hydrophilicity and antifouling properties of PVC/PVC- $g$-PEGMA blended membranes by mixing common solvents. Moreover, we hoped to provide more studies for the blended system of PVC/PVC-g-PEGMA blended membranes.

\section{Materials and methods}

\subsection{Materials}

PVC (high molecular weight), PVC-g-PEGMA (synthesized and verified in our previous work ${ }^{\mathbf{1 8}}$ based on the method previously described $^{20}$ ), 1-methyl-2-pyrrolidinone (NMP, anhydrous, $99.5 \%$ ), sodium chloride ( $\mathrm{NaCl}$, ACS reagent, $\geq 99.0 \%$ ), sodium alginate (SA, Halal grade) and tetrahydrofuran (THF, anhydrous, $\geq 99.9 \%$, inhibitor-free) were purchased from MilliporeSigma (St. Louis, MO, USA).

\subsection{Membrane preparation}

The fabrication of membrane was similar to that of the previous study. ${ }^{21}$ The membrane casting solution was prepared in $125 \mathrm{~mL}$ conical flasks according to Table 2 and stirred at $500 \mathrm{rpm}$ by a stirring hot plate (PC-420D, Corning, USA) at $60{ }^{\circ} \mathrm{C}$ for at least $24 \mathrm{~h}$. After the polymers were completely dissolved, the solution was degassed without stirring for at least $3 \mathrm{~h}$ until gas bubbles were not completely observed, and then it was cast on a first-grade surface optical glass using a doctor blade set to a thickness of $\sim 200 \mu \mathrm{m}$ (Universal blade applicator, Paul N. Gardner Company, Inc., Pompano Beach, FL, USA). Before immersed into a coagulation bath of deionized (DI) water at room temperature for $24 \mathrm{~h}$, the mirror was exposed in air for different time according to Table 2 to allow the solvent to evaporate. Finally, part of membranes immersed in ultrapure water were stored at $4{ }^{\circ} \mathrm{C}$ for flux and

Table 2 Compositions of the membrane casting solutions ${ }^{a}$

\begin{tabular}{|c|c|c|c|c|c|c|}
\hline Membrane ID & PVC (g) & $\begin{array}{l}\text { PVC- } g \text {-PEGMA } \\
(\mathrm{g})\end{array}$ & THF (g) & NMP (g) & $\begin{array}{l}\text { Solvent evaporation } \\
\text { time }(\mathrm{s})\end{array}$ & $\begin{array}{l}\text { PVC- } g \text {-PEGMA/PVC } \\
\text { wt/wt }(\%)\end{array}$ \\
\hline M1 NMP $60 \mathrm{~s}$ & 12 & 1.2 & - & 86.80 & 60 & 10 \\
\hline $\mathrm{M} 2 \mathrm{~T} / \mathrm{N}=1 / 90 \mathrm{~s}$ & 12 & 1.2 & 8.68 & 78.12 & 0 & 10 \\
\hline $\mathrm{M} 3 \mathrm{~T} / \mathrm{N}=1 / 930 \mathrm{~s}$ & 12 & 1.2 & 8.68 & 78.12 & 30 & 10 \\
\hline $\mathrm{M} 4 \mathrm{~T} / \mathrm{N}=1 / 960 \mathrm{~s}$ & 12 & 1.2 & 8.68 & 78.12 & 60 & 10 \\
\hline $\mathrm{M} 5 \mathrm{~T} / \mathrm{N}=1 / 990 \mathrm{~s}$ & 12 & 1.2 & 8.68 & 78.12 & 90 & 10 \\
\hline $\mathrm{M} 6 \mathrm{~T} / \mathrm{N}=3 / 760 \mathrm{~s}$ & 12 & 1.2 & 26.04 & 60.76 & 60 & 10 \\
\hline $\mathrm{M} 7 \mathrm{~T} / \mathrm{N}=5 / 560 \mathrm{~s}$ & 12 & 1.2 & 43.40 & 43.40 & 60 & 10 \\
\hline
\end{tabular}

${ }^{a}$ At $25{ }^{\circ} \mathrm{C}$, the density of THF is $0.889 \mathrm{~g} \mathrm{~mL}^{-1}$, NMP is $1.028 \mathrm{~g} \mathrm{~mL}^{-1}$. T/N means the weight/weight ratio of THF to NMP. 
fouling tests, and the others were air-dried for the characterizations.

\subsection{Model foulant}

Sodium alginate (SA) as a model foulant of extracellular polymeric substances (EPS) to assess the anti-fouling properties of membrane was studied..$^{22-24}$ A $2 \mathrm{~g} \mathrm{~L}^{-1}$ SA stock solution was stored at $4{ }^{\circ} \mathrm{C}$. The SA concentration in the filtration test was determined by an UV-vis spectrometer (Thermo Orion Aquamate 8000, USA) at a constant wavelength of $210 \mathrm{~nm}^{\mathbf{1 8}}$

\subsection{Membrane characterization}

A fourier transform infrared spectroscopy (FTIR) spectrometer with a germanium ATR attachment (FTIR-ATR) (ALPHA, Bruker, Germany) was used to analyze the $\mathrm{C}=\mathrm{O}$ and the $\mathrm{C}=\mathrm{C}$ stretching band to determine whether PVC-g-PEGMA exist on the blended membrane surfaces. The oxygen, chlorine, and carbon elements on the near surface of all membranes were measured by X-ray photoelectron spectroscopy (XPS) (Axis Ultra, Kratos Analytical Ltd., UK) in the range from 0 to $1100 \mathrm{eV}$. The morphologies of all blended membranes were imaged using field-emission scanning electron microscopy (FESEM) (JSM-7500F, JEOL Ltd., Tokyo, Japan) at $15 \mathrm{kV}$ accelerating voltage. The hydrophilicity of the membrane surface was characterized by dynamic water contact angle measured using a KRÜSS DSA 25S measuring apparatus (KRÜSS GmbH, Germany). The surface roughness of all blended membranes was determined using atomic force microscopy (AFM) (Multimode 8, Bruker, Germany) at a scan rate of $0.977 \mathrm{~Hz}$ and a scan size of $5 \mu \mathrm{m} \times 5 \mu \mathrm{m}$.

The membrane bulk porosity was measured by its dry and wet weights. First, the membrane stored in DI water was weighed after wiping off the water on the membrane surface with laboratory wipes. Second, the dry weight was measured after the wet membrane was dried at $30{ }^{\circ} \mathrm{C}$ for at least $24 \mathrm{~h}$ in a vacuum oven. The bulk porosity of the membrane was determined according to the following eqn (1). ${ }^{25}$

$$
\varepsilon(\%)=\frac{M_{\mathrm{w}}-M_{\mathrm{d}}}{\rho_{\mathrm{w}} A_{\mathrm{m}} \delta} \times 100
$$

where $\varepsilon$ is the membrane bulk porosity, $M_{\mathrm{w}}(\mathrm{g})$ is the weight of wet membrane, $M_{\mathrm{d}}(\mathrm{g})$ represents the weight of dry membrane, $P_{\mathrm{w}}\left(\mathrm{g} \mathrm{cm}^{-3}\right)$ is the pure water density $\left(4^{\circ} \mathrm{C}, 1 \mathrm{~g} \mathrm{~cm}^{-3}\right), A_{\mathrm{m}}\left(\mathrm{cm}^{2}\right)$ represents the area of the wet membrane, and $\delta(\mathrm{cm})$ is the thickness of the wet membrane.

\subsection{Ultrafiltration experiments}

The membrane filtration test was conducted using a $200 \mathrm{~mL}$ dead-end filtration cell (Amicon 8200, Millipore, USA), and the filtration cell was connected to a $5.0 \mathrm{~L}$ dispensing vessel which was attached a high-purity nitrogen tank. The effective filtration area was $28.7 \mathrm{~cm}^{2}$. A Pro Balance (AV8101, Ohaus Adventurer, USA) was used to weigh the permeate, and the permeate mass data was recorded every minute using Collect 6.1 software. The transmembrane pressure (TMP) in all flux tests was 20 psi.

The experimental procedures for evaluating the flux performance are described as follows according to previous reports. ${ }^{\mathbf{4 2 1}}$
First, the pure water flux $\left(J_{\mathrm{w} 1}, \mathrm{~L} \mathrm{~m}^{-2} \mathrm{~h}^{-1}\right)$ of the wet membrane was measured by filtering DI water for $2 \mathrm{~h}$. Second, the membrane was conditioned for $2 \mathrm{~h}$ using a $10 \mathrm{mM} \mathrm{NaCl}$ solution. Then, the fouling experiment was measured for $7 \mathrm{~h}$ by filtering a feed solution comprising $20 \mathrm{mgL}^{-1} \mathrm{SA}$ and $10 \mathrm{mM} \mathrm{NaCl}$ with stirring at $200 \mathrm{rpm}$. The flux of the feed solution was denoted as $J_{\mathrm{p}}, \mathrm{L} \mathrm{m}^{-2}$ $\mathrm{h}^{-1}$. Finally, the fouled membrane was flushed by DI water for $3 \mathrm{~min}$, and the flux $\left(J_{\mathrm{w} 2}, \mathrm{~L} \mathrm{~m}^{-2} \mathrm{~h}^{-1}\right)$ of the cleaned membrane was measured. The membrane filtration tests were repeated at least twice and the average value was reported. The antifouling properties of the membrane were evaluated with some ratios like the flux recovery ratio $(F R R)$, the total flux decline ratio $\left(D_{t}\right)$, reversible flux decline ratio $\left(\mathrm{DR}_{\mathrm{r}}\right)$, and irreversible flux decline ratio $\left(D_{i r}\right)$ which were calculated with the following equations from some previous literature. ${ }^{26,27}$ Higher FRR and lower $\mathrm{DR}_{\mathrm{t}}$ indicate better antifouling properties of the membrane. ${ }^{28}$

$$
\begin{gathered}
\mathrm{FRR}=\frac{J_{\mathrm{w} 2}}{J_{\mathrm{w} 1}} \times 100 \% \\
\mathrm{DR}_{\mathrm{t}}=\left(1-\frac{J_{\mathrm{p}}}{J_{\mathrm{w} 1}}\right) \times 100 \% \\
\mathrm{DR}_{\mathrm{r}}=\left(\frac{J_{\mathrm{w} 2}-J_{\mathrm{p}}}{J_{\mathrm{w} 1}}\right) \times 100 \% \\
\mathrm{DR}_{\mathrm{ir}}=\left(\frac{J_{\mathrm{w} 1}-J_{\mathrm{w} 2}}{J_{\mathrm{w} 1}}\right) \times 100 \%
\end{gathered}
$$

\section{Results and discussion}

\subsection{The effects of solvent and nonsolvent on membranes}

The relative affinity of solvent with PVC and water is evaluated using the distance in their Hansen solubility parameter space $\left(R_{\mathrm{HSP}}\right)$, which was calculated by following eqn (6). ${ }^{29}$

$$
R_{\mathrm{HSP}}=\sqrt{4\left(\delta_{\mathrm{d} 1}-\delta_{\mathrm{d} 2}\right)^{2}+\left(\delta_{\mathrm{p} 1}-\delta_{\mathrm{p} 2}\right)^{2}+\left(\delta_{\mathrm{h} 1}-\delta_{\mathrm{h} 2}\right)^{2}}
$$

where the " 1 " represents solvent, " 2 " represents polymer or water, $\delta_{\mathrm{d}}, \delta_{\mathrm{p}}$ and $\delta_{\mathrm{h}}$ are the dispersion component, polar component and hydrogen bonding component of Hansen solubility parameter (HSP), respectively.

The HSP of PVC, water and solvents, and $R_{\mathrm{HSP}}$ values of solvent-PVC pair and solvent-water pair are listed in Table 3. The lower $R_{\mathrm{HSP}}$ value of solvent-polymer pair indicates the better dissolving ability of a solvent. A better solvent has a stronger interaction with the polymer..$^{30} R_{\mathrm{HSP}}$ values of NMPPVC, THF-PVC and DMAc-PVC are 4.9 $\mathrm{MPa}^{1 / 2}, 7.5 \mathrm{MPa}^{1 / 2}$, and 8.2 $\mathrm{MPa}^{1 / 2}$, respectively, which indicates that the order of interaction between the three solvents and PVC is NMP $>$ THF $>$ DMAc. Selection of solvent and non-solvent pair is the key factor in preparation of membranes fabricated by non-solvent induced phase separation (NIPS) method. ${ }^{31}$ The lower $R_{\mathrm{HSP}}$ value of water-solvent pair means the better interaction between them, which leads to faster exchange of water and solvent during membrane immersion in water. ${ }^{12}$ The $R_{\mathrm{HSP}}$ value of the THF-water is larger than that of the NMP-water. 
Table 3 Hansen solubility parameter of solvents, water, PVC and their HSP distance $\left(R_{\mathrm{HSP}}\right)^{a}$

\begin{tabular}{lllllll}
\hline & \multicolumn{3}{l}{$\begin{array}{l}\text { Hansen solubility } \\
\text { parameter }\left(\mathrm{MPa}^{1 / 2}\right)\end{array}$} & & \multicolumn{2}{l}{$R_{\mathrm{HSP}}\left(\mathrm{MPa}^{1 / 2}\right)$} \\
Material & $\delta_{\mathrm{d}}$ & $\delta_{\mathrm{p}}$ & $\delta_{\mathrm{h}}$ & & Solvent-PVC & Solvent-water \\
\hline THF & 16.8 & 5.7 & 8 & & 7.5 & 35.91 \\
NMP & 18 & 12.3 & 7.2 & & 4.9 & 35.65 \\
DMAc & 16.8 & 11.5 & 10.2 & 8.2 & 32.52 \\
Water & 15.5 & 16 & 42.3 & - & - \\
PVC & 18.7 & 10 & 3.1 & - & -
\end{tabular}

${ }^{a} R_{\mathrm{HSP}}$ is calculated by eqn (6). Hansen solubility parameter of solvents, ${ }^{29}$ water ${ }^{29}$ PVC. ${ }^{33}$

Therefore, in the current system, THF can theoretically prolong the phase separation, thus suppressing the formation of macrovoids and porous surface layer, which is beneficial to the formation of dense surface layer. ${ }^{32}$

\subsection{Analysis of near-surface compositions of all blended membranes}

Fig. 1 exhibits FTIR-ATR spectra for the top surface of all blended membranes prepared at different solvents' mixing ratio and varied solvent evaporation time, which is used to prove the presence of PVC-g-PEGMA on the membrane surface. The $\mathrm{C}=\mathrm{O}$ stretching band is represented by the vibrational band at $1727 \mathrm{~cm}^{-1},{ }^{34}$ and the peak at $1638 \mathrm{~cm}^{-1}$ represents the $\mathrm{C}=\mathrm{C}$ stretching band. ${ }^{35}$ As shown in Fig. 1, the characteristic peak at $1727 \mathrm{~cm}^{-1}$ but no peak at $1638 \mathrm{~cm}^{-1}$ was observed on all membranes, which indicated the existence of amphiphilic copolymer PVC-g-PEGMA on the surface of all blended membranes.

In order to analyze the chemical elements on the near surface of PVC/PVC- $g$-PEGMA blended ultrafiltration membranes in more detail, the near-surface chemical compositions of the membrane were determined by XPS, shown in

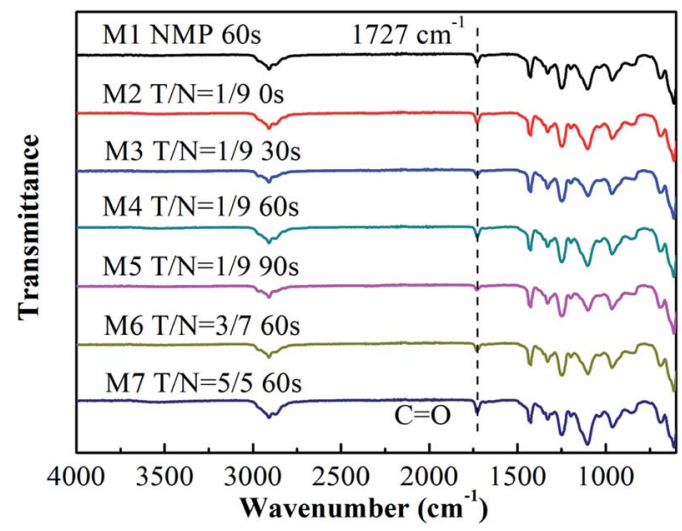

Fig. 1 FTIR-ATR spectra of the blended membranes at different THF : NMP ratios and different solvent evaporation time. M1, NMP, $60 \mathrm{~s} ; M 2, T / N=1: 9,0 \mathrm{~s} ; M 3, T / N=1: 9,30 \mathrm{~s} ; M 4, T / N=1: 9,60 \mathrm{~s}$; $M 5, T / N=1: 9,90 \mathrm{~s} ; M 6, T / N=3: 7,60 \mathrm{~s} ; M 7, T / N=5: 5,60 \mathrm{~s}$.
Fig. 2. Surface separation commonly occurs in blend systems with amphiphilic polymer during the NIPS process. ${ }^{36}$ In this work, the PEGMA segments of PVC-g-PEGMA tended to migrate to the membrane surface during the formation of the membrane, being the only source of oxygen element on the membrane surface. Therefore, the near-surface oxygen content of the membrane suggested the migration level of the PEGMA segments. All prepared membranes were blended PVC with the same amount of PVC-g-PEGMA (10 wt\%). However, the oxygen content of the membrane surface was different when the amount of THF and solvent evaporation time were varied, which meant both amount of THF and solvent evaporation time had an impact on the migration of PEGMA segments onto the membrane surface.

As presented in Fig. 2a, d, f and g, the surface of membrane M1 (prepared with only NMP as solvent) had the most oxygen content of $14.41 \%$. The near-surface oxygen content of membranes M4, M6 and M7 was $10.97 \%, 10.84 \%$ and $10.95 \%$, respectively, which indicated that adding THF as a co-solvent in the casting solution reduced the oxygen content on the membrane surface. However, with increasing the amount of THF, the near-surface oxygen content was basically the same. This phenomenon probably could be explained as follows: THF evaporated selectively during 60 seconds of evaporation, thus forming the nascent top layer, ${ }^{15}$ which probably prevented the migration of PEGMA segments to the membrane surface. Therefore, when the mixing ratio of THF to NMP was $1: 9$, the oxygen content on the membrane surface decreased significantly from $14.41 \%$ to $10.97 \%$. Meanwhile, the solvent evaporation time before immersion in DI water was the same for $60 \mathrm{~s}$, thus the nascent top layer formed during evaporation had the same hindrance effect on the migration of PEGMA segments. Therefore, even though the THF/NMP mixing ratio increased from $1: 9$ to $5: 5$, the oxygen content on the membrane surface was almost unchanged.

Fig. 2b-e shows the XPS spectra of the blended membranes fabricated at different evaporation times under the same THF/ NMP ratio of $1: 9$. The near-surface oxygen content of membranes M2, M3, M4 and M5 was 8.42\%, 9.08\%, 10.97\% and $10.46 \%$, respectively. That was to say, the near-surface oxygen content of the membranes increased with increasing solvent evaporation time from $0 \mathrm{~s}$ to $60 \mathrm{~s}$, but when evaporation time continued to increase to $90 \mathrm{~s}$, the oxygen content decreased slightly. This might be because as solvent evaporation time increased, higher polymer concentration was obtained at the surface of the casting membrane before immersion in DI water. Therefore, the exchanging of solvent and DI water was slowed down, which gave PEGMA segments more time to move to the membrane surface. ${ }^{37}$ However, when solvent evaporation time continued to increase from $60 \mathrm{~s}$ to $90 \mathrm{~s}$, the nascent skin layer formed during evaporation hindered the migration of PEGMA segments to the membrane surface, hence the oxygen content decreased slightly. Combined with the analysis of paragraph above, we speculated that solvent evaporation for $60 \mathrm{~s}$ initiates the formation of a nascent surface layer, which will hinder the migration of PEGMA segments to the membrane surface during the phase inversion process. 

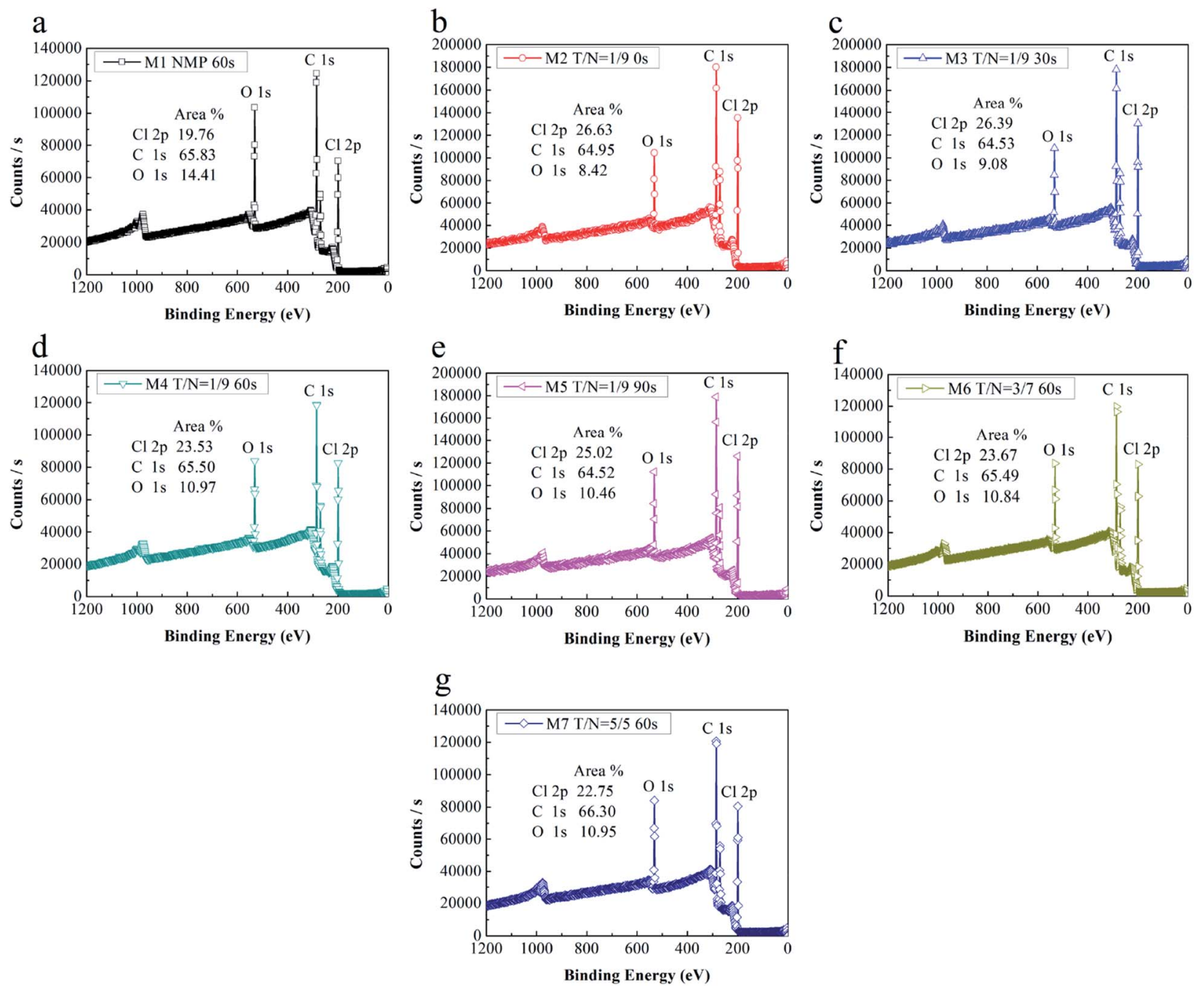

Fig. 2 XPS spectra of all blended membranes: (a) M1, NMP, $60 \mathrm{~s}$; (b) M2, T/N=1/9, $0 \mathrm{~s}$; (c) M3, T/N =1/9, 30 s; (d) M4, T/N =1/9, 60 s; (e) M5, T/N $=1 / 990 \mathrm{~s}$; (f) $M 6, T / N=3 / 7,60 \mathrm{~s}$; (g) $M 7, T / N=5 / 5,60 \mathrm{~s}$.

\subsection{Morphologies of all blended membranes}

Fig. 3 shows the morphologies of all blended membranes observed by the SEM. The surface pore size distribution of the membranes is summarized in Table 4, except for membrane M7, because its surface pore cannot be observed in the SEM image. As presented in Fig. 3a, g, k, $\mathrm{m}$ and Table 4, the average diameter $\left(D_{\text {average }}\right)$, pore density and porosity of membrane M1 were the largest. After adding THF, the $D_{\text {average }}$, pore density and porosity of membranes M4, M6 and M7 were smaller than those of membrane M1. This was because the rapid evaporation of THF as a co-solvent during the evaporation stage enriched the polymer concentration on the surface of the casting membrane, resulting in a denser or pore-free surface layer. ${ }^{17}$ Moreover, compared with membranes M4, M6 and M7, it was found that the $D_{\text {average, }}$ pore density and porosity of the membrane decreased with increasing the amount of THF. The crosssection of the fabricated membrane can be divided into three parts, the dense top layer, the porous finger-like structures, and macrovoids. As shown in Fig. 3b, h, l and n, membranes M1,
M4, M6 and M7 all exhibited asymmetric structures and large macrovoids. The heights of the macrovoids of membranes M1, M4, M6, and M7 measured using Image Pro Plus V.7.0 software (Vashaw Scientific Inc.) were $75.442 \mu \mathrm{m}, 67.703 \mu \mathrm{m}, 49.925 \mu \mathrm{m}$, $43.178 \mu \mathrm{m}$, respectively. This result showed that the large macrovoids became smaller as the amount of THF increased. This result is in accordance with the bulk porosity of the fabricated membranes (Table 5), which is in the order of $\mathrm{M} 7<$ M6 $<$ M4 $<$ M1. However, the existence of macrovoids in the cross-section of membranes is usually detrimental, as this will form weak spots within the membrane, especially in the condition with high pressure. ${ }^{31}$ As mentioned in Section 3.1, THF can increase the time of phase separation due to its worse affinity with water compared to NMP, which can inhibit the formation of macrovoids and porous surface layer. ${ }^{32}$ The more THF is added, the longer the time of phase separation is, thus the inhibition for the formation of macrovoids is stronger. ${ }^{15}$ Therefore, the $D_{\text {average, }}$ pore density and porosity of the membrane decreased with increasing THF/NMP ratio, and the 

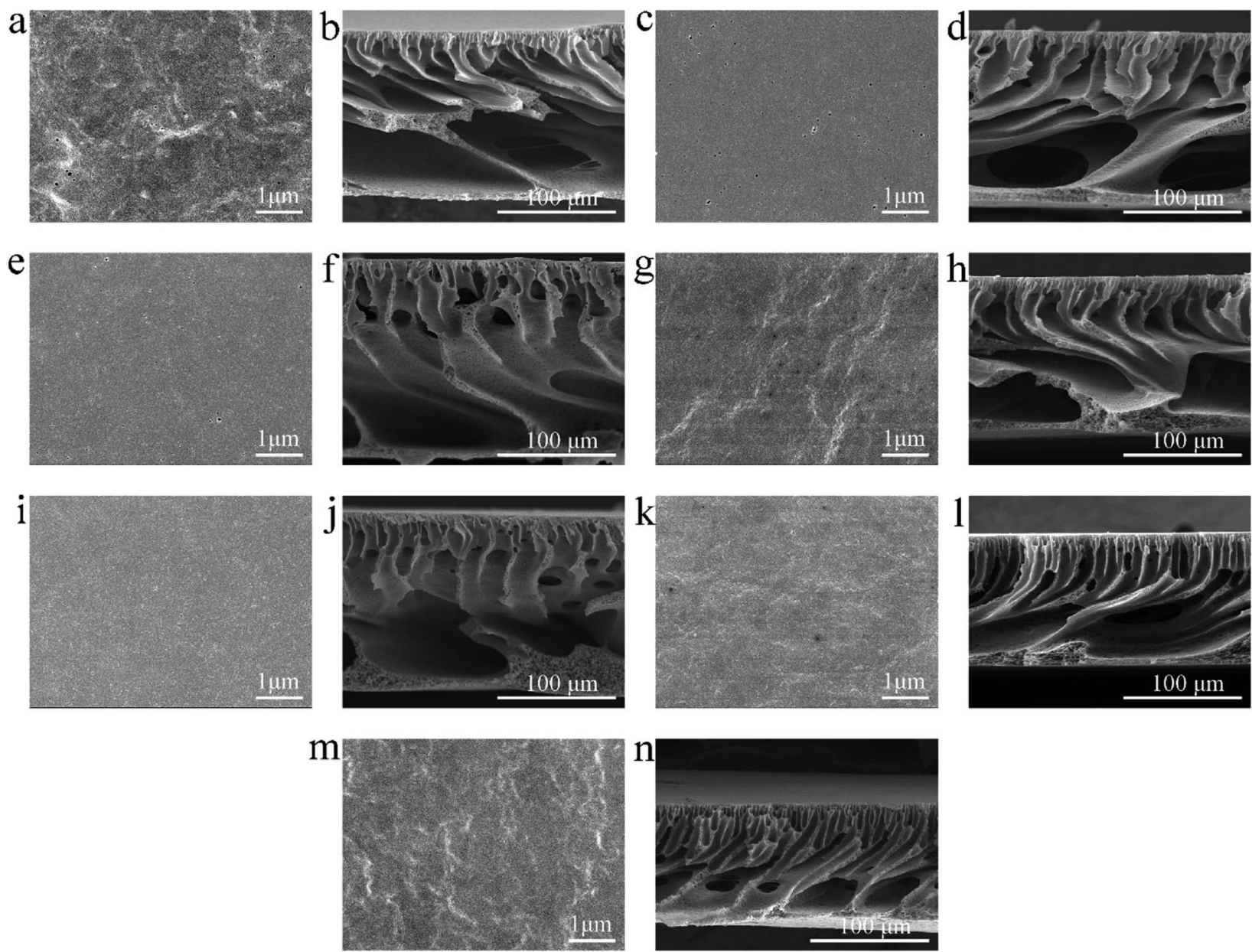

Fig. 3 Surface and cross-sectional morphologies of all blended membranes: (a and b) M1, NMP, $60 \mathrm{~s}$; (c and d) M2, T/N =1/9, 0 s; (e and f) M3, T/ $\mathrm{N}=1 / 9,30 \mathrm{~s}$; ( $\mathrm{g}$ and $\mathrm{h}$ ) $M 4, T / N=1 / 9,60 \mathrm{~s}$; (i and j) $M 5, T / N=1 / 9,90 \mathrm{~s}$; (k and l) M6, T/N =3/7, $60 \mathrm{~s}$; (m and $\mathrm{n}) \mathrm{M7}, \mathrm{T} / \mathrm{N}=5 / 5,60 \mathrm{~s}$.

structure of membranes M6 and M7 was denser than that of membranes M1 and M4.

As shown in Fig. 3c, e, g, i and Table 4 (membranes M2, M3, M4 and M5), when the THF/NMP mixing ratio was $1: 9$, the $D_{\text {average }}$ decreased with the increase of evaporation time in general, which was consistent with the result reported in the previous literature. ${ }^{38}$ The surface pore density and porosity of the membrane also decreased with increasing evaporation time, which was due to the higher polymer concentration at the interface resulted from longer evaporation time. As shown in Fig. 3d, f, h and j, membranes M2, M3, M4 and M5 all exhibited asymmetric structures with macrovoids, but the cross-sectional structure of the membranes did not change much as evaporation time increased from $0 \mathrm{~s}$ to $90 \mathrm{~s}$. Hołda et $a .^{9}{ }^{9}$ prepared polysulfone (PSf) solvent resistant nanofiltration membranes with $3 / 7$ of THF/NMP as solvent, distilled water as coagulation bath under $21 \mathrm{wt} \%$ of polymer concentration. They found that the number of macrovoids decreased when evaporation time increased, but its shape remained the same. When the solvent evaporated for $120 \mathrm{~s}$, the macrovoids disappeared. This suggested that solvent evaporation could inhibit the formation of macrovoids before the

Table 4 The surface pore size distribution of the blended membranes

\begin{tabular}{|c|c|c|c|c|}
\hline Membrane ID & $D_{\text {average }}(\mathrm{nm})$ & $D_{\max }(\mathrm{nm})$ & Pore density $\left(\mathrm{m}^{-2}\right)$ & Porosity (\%) \\
\hline M1 NMP $60 \mathrm{~s}$ & 14.79 & 64.53 & $4.03 \times 10^{12}$ & 0.106 \\
\hline $\mathrm{M} 2 \mathrm{~T} / \mathrm{N}=1 / 90 \mathrm{~s}$ & 14.53 & 50.38 & $10.10 \times 10^{12}$ & 0.240 \\
\hline $\mathrm{M} 4 \mathrm{~T} / \mathrm{N}=1 / 960 \mathrm{~s}$ & 13.89 & 30.98 & $1.64 \times 10^{12}$ & 0.036 \\
\hline $\mathrm{M} 5 \mathrm{~T} / \mathrm{N}=1 / 990 \mathrm{~s}$ & 7.22 & 19.60 & $1.45 \times 10^{12}$ & 0.008 \\
\hline $\mathrm{M} 6 \mathrm{~T} / \mathrm{N}=3 / 760 \mathrm{~s}$ & 7.53 & 21.94 & $0.93 \times 10^{12}$ & 0.005 \\
\hline
\end{tabular}


Table 5 The bulk porosity, pure water flux and SA rejection ratio of all blended membranes

\begin{tabular}{lccc}
\hline Membrane ID & Bulk porosity ${ }^{a}(\%)$ & Pure water flux $\left(\mathrm{L} \mathrm{m}^{-2} \mathrm{~h}^{-1}\right)$ & SA rejection ratio $(\%)$ \\
\hline M1 NMP 60 s & $91.95 \pm 0.04$ & $226.06 \pm 5.71$ & $91.05 \pm 3.38$ \\
M2 T/N $=1 / 90 \mathrm{~s}$ & $92.89 \pm 0.01$ & $254.11 \pm 38.68$ & $86.10 \pm 1.48$ \\
M3 T/N $=1 / 930 \mathrm{~s}$ & $92.60 \pm 1.87$ & $247.25 \pm 35.19$ & $89.16 \pm 0.71$ \\
M $\mathrm{T} / \mathrm{N}=1 / 960 \mathrm{~s}$ & $91.52 \pm 2.07$ & $141.54 \pm 30.18$ & $92.12 \pm 0.63$ \\
M5 T/N $=1 / 990 \mathrm{~s}$ & $82.63 \pm 1.83$ & $138.16 \pm 8.92$ & $92.21 \pm 0.40$ \\
M6 T/N $=3 / 760 \mathrm{~s}$ & $89.91 \pm 0.91$ & $73.10 \pm 6.70$ & $92.47 \pm 1.73$ \\
M7 T/N $=5 / 560 \mathrm{~s}$ & $83.56 \pm 2.89$ & & $92.16 \pm 0.48$ \\
${ }^{a}$ Calculated by eqn (1). & & &
\end{tabular}

casting solution was immersed in the coagulation bath. However, in the current system, solvent evaporation did not obviously control the macrovoids. There might be three reasons: (1) the polymer concentration was very low, only $13.2 \%$; (2) the amount of THF was very small, and the ratio of THF to NMP was only $1: 9$; (3) as described in our previous study ${ }^{18}$ amphiphilic copolymer PVC-g-PEGMA existed in the blend system, which helped to accelerate the exchange between solvent and non-solvent, thus weakening the inhibition of solvent evaporation on macrovoids formation.

\subsection{AFM analysis}

As exhibited in Fig. 4, the root mean square (RMS) roughness of the membrane surface generally decreased with increasing
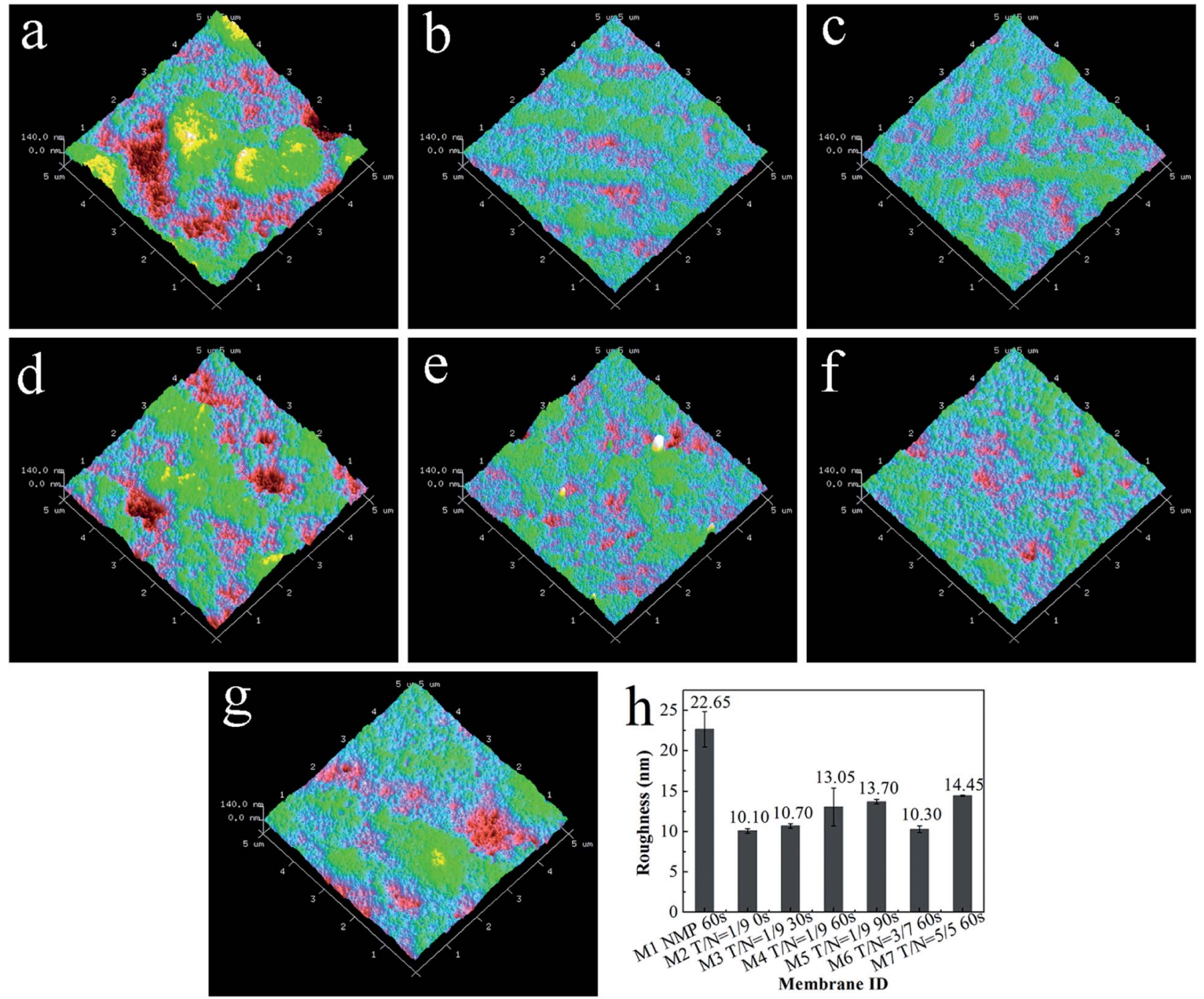

Fig. 4 AFM images of all blended membranes: (a) M1, NMP, $60 \mathrm{~s}$; (b) M2, T/N=1/9, 0 s; (c) M3, T/N =1/9, 30 s; (d) M4, T/N =1/9, 60 s; (e) M5, T/N $=1 / 9,90 \mathrm{~s}$; (f) $M 6, T / N=3 / 7,60 \mathrm{~s}$; (g) $M 7, T / N=5 / 5,60 \mathrm{~s}$; (h) the RMS roughness of all blended membranes. 
THF/NMP mixing ratio but increased as solvent evaporation time, which was consistent with changes in oxygen content of the membrane surface. Combined with the results in our previous study, ${ }^{18}$ we ascertained that the more PVC- $g$-PEGMA on the membrane surface, the rougher the membrane surface. In this work, the addition of THF could significantly lower the surface roughness of the membrane and the casting membrane should not evaporate for too long before immersion in the coagulation bath.

\subsection{Hydrophilicity analysis of the blended membranes}

As presented in Fig. 5, the water contact angle of all blended membranes declined with time. For the case of increasing THF/ NMP mixing ratio, the initial water contact angle of membranes M1, M4, M6 and M7 was $70.38 \pm 0.98^{\circ}, 70.87 \pm 1.24^{\circ}, 70.46 \pm$ $1.09^{\circ}$ and $70.45 \pm 1.19^{\circ}$, respectively. In other words, the water contact angle was similar for the membrane M1 and the membranes M4, M6, M7, which was probably due to the synergistic effect of hydrophilic PEGMA segments on the membrane surface and the surface roughness of the membrane. Membrane M1 had the most hydrophilic PEGMA segments on the surface, but simultaneously, its surface roughness was higher than that of membranes M4, M6, M7. The hydrophilicity and the roughness of the membrane surface can impact the change of contact angle. ${ }^{39,40}$ The surface oxygen content of membranes M4, M6 and M7 was almost the same, and their surface roughness was similar. Therefore, the initial water contact angles of membranes M4, M6 and M7 were similar.

When the THF/NMP mixing ratio was $1: 9$, the initial water contact angle of the blended membranes first declined from $76.32 \pm 1.55^{\circ}$ to $70.82 \pm 1.24^{\circ}$ with increasing solvent evaporation time from $0 \mathrm{~s}$ to $60 \mathrm{~s}$ and then increased to $72.00 \pm 2.03^{\circ}$ when evaporation time increased to $90 \mathrm{~s}$. This result suggested that increasing evaporation time properly could enrich the hydrophilic PEGMA segments on the membrane surface, thus enhancing the hydrophilicity of the membrane.

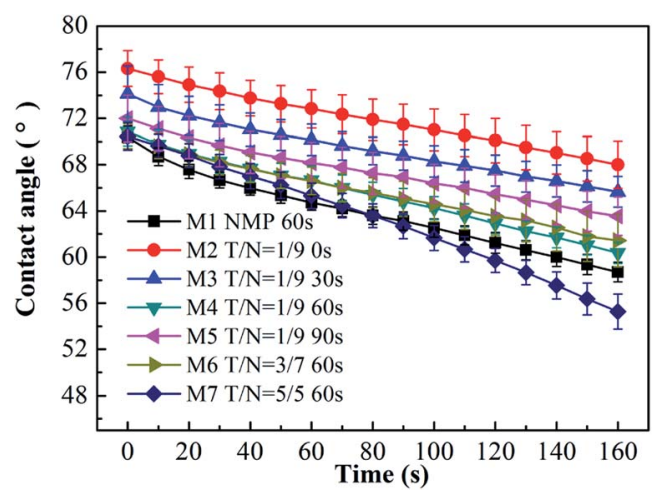

Fig. 5 Change of water contact angle for all blended membranes at different THF/NMP ratios and different solvent evaporation time. M1, NMP, $60 \mathrm{~s} ; \mathrm{M} 2, \mathrm{~T} / \mathrm{N}=1: 9,0 \mathrm{~s} ; \mathrm{M} 3, \mathrm{~T} / \mathrm{N}=1: 9,30 \mathrm{~s} ; \mathrm{M} 4, \mathrm{~T} / \mathrm{N}=1: 9$, $60 \mathrm{~s} ; M 5, T / N=1: 9,90 \mathrm{~s} ; M 6, T / N=3: 7,60 \mathrm{~s} ; M 7, T / N=5: 5,60 \mathrm{~s}$.

\subsection{Filtration performance}

Fig. 6 shows the flux performance of the blended membranes under a constant pressure of $20 \mathrm{psi}$ at room temperature $\left(\sim 25^{\circ} \mathrm{C}\right)$. As shown in Fig. 6 and Table 5, both the amount of THF and the solvent evaporation time could significantly affect the pure water fluxes of the membranes. For the case of different THF/NMP mixing ratio, membrane $\mathrm{M} 1$ exhibited the highest pure water flux of $226.06 \pm 5.71 \mathrm{~L} \mathrm{~m}^{-2} \mathrm{~h}^{-1}$. The pure water flux decreased to $24.85 \pm 0.45 \mathrm{~L} \mathrm{~m}^{-2} \mathrm{~h}^{-1}$ with increasing THF : NMP mixing ratio to $5: 5$. The pure water flux of the membrane is affected by hydrophilicity, pore size, porosity and transmembrane pressure.

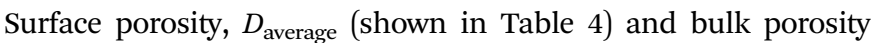
(shown in Table 5) of the membrane decreased with increasing the amount of THF, which caused a decrease in the pure water flux of the membrane. Moreover, the SA rejection ratios of the blended membranes increased as THF/NMP mixing ratio increased, which was probably due to the decreased $D_{\text {average }}$ and maximum diameter $\left(D_{\max }\right)$ of the membrane. For the case of changing evaporation time, the water pure flux of the membrane declined from $254.11 \pm 38.68 \mathrm{~L} \mathrm{~m}^{-2} \mathrm{~h}^{-1}$ to $138.16 \pm 8.92 \mathrm{~L} \mathrm{~m}^{-2}$ $\mathrm{h}^{-1}$ as the solvent evaporation time increased, which was probably because of the decreased surface porosity, $D_{\text {average }}$ and bulk porosity of the membrane. In addition, the decrease of maximum diameter $\left(D_{\max }\right)$ resulted in higher SA rejection ratio for membranes M2, M3, M4, M5.

Characterization of the antifouling properties for all blended membranes are shown in Fig. 7. For the case of increasing THF/NMP mixing ratio, the flux recovery ratio (FRR) of membranes M1, M4, M6 and M7 was $88.21 \pm 10.13 \%$, $98.65 \pm 0.85 \%, 92.79 \pm 2.71 \%$, and $81.81 \pm 7.22 \%$, respectively. The FRR of membrane M1 was lower than that of membranes M4 and M6, which was probably due to larger surface pore size ${ }^{\mathbf{4 1}}$ and higher surface roughness ${ }^{\mathbf{4 2}}$ of membrane M1 comparing with membranes M4 and M6. The FRR of membrane M7 was lower than that of membranes M4 and M6, which probably was because the surface roughness of membrane $\mathrm{M} 7$ was larger than that of membranes M4 and M6. For the case of varied solvent evaporation time, the FRR of membranes M2, M3, M4, and M5 was $92.20 \pm 3.83 \%, 96.48 \pm 3.35 \%, 98.65 \pm 0.85 \%, 96.44 \pm$

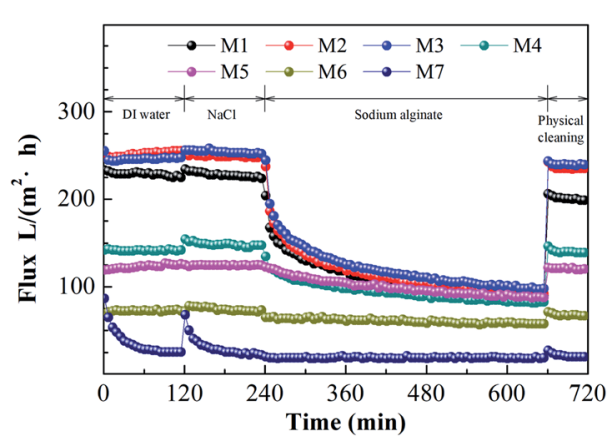

Fig. 6 Flux as a function of time using DI water or SA as feed solution of the PVC/PVC-g-PEGMA membranes fabricated at different THF/ NMP ratio and solvent evaporation time. M1: NMP, $60 \mathrm{~s} ; \mathrm{M} 2, \mathrm{~T} / \mathrm{N}=$ $1: 9,0 \mathrm{~s} ; M 3, T / N=1: 9,30 \mathrm{~s} ; M 4, T / N=1: 9,60 \mathrm{~s} ; M 5, T / N=1: 9$, $90 \mathrm{~s} ; M 6, T / N=3: 7,60 \mathrm{~s} ; M 7, T / N=5: 5,60 \mathrm{~s}$. 


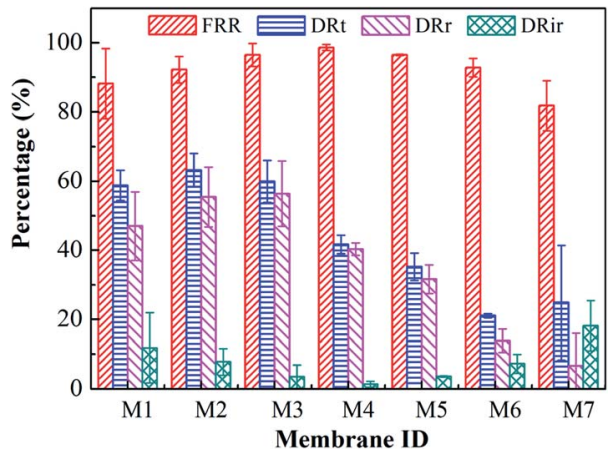

Fig. 7 Characterization of the membrane antifouling properties: the flux recovery ratio (FRR), total flux decline ratio $\left(D R_{t}\right)$, reversible flux decline ratio $\left(D R_{r}\right)$, and irreversible flux decline ratio $\left(D R_{\text {ir }}\right)$. M1, NMP, $60 \mathrm{~s} ; M 2, T / N=1: 9,0 \mathrm{~s} ; M 3, T / N=1: 9,30 \mathrm{~s} ; M 4, T / N=1: 9,60 \mathrm{~s}$; $M 5, T / N=1: 9,90 \mathrm{~s} ; M 6, T / N=3: 7,60 \mathrm{~s} ; M 7, T / N=5: 5,60 \mathrm{~s}$.

$0.19 \%$, and the $\mathrm{DR}_{\mathrm{t}}$ of them was $63.21 \pm 4.86 \%, 59.91 \pm 6.11 \%$, $41.67 \pm 2.65 \%$, and $35.21 \pm 3.91 \%$, respectively. The FRR generally increased and the $\mathrm{DR}_{\mathrm{t}}$ decreased as solvent evaporation time increased, which was due to the increase of hydrophilicity. ${ }^{43}$ Overall, membrane M4 exhibited the best antifouling properties with high pure water flux and SA rejection rate simultaneously.

\section{Conclusion}

In this work, we investigated the effect of THF as co-solvent and the solvent evaporation time on the performances of PVC/PVC$g$-PEGMA blended membranes. When the THF/NMP mixing ratio was up to $3: 7$, the macrovoids at the bottom layer could become smaller. The addition of THF could effectively reduce the surface roughness of PVC/PVC- $g$-PEGMA membranes, thus improving its antifouling properties. Increasing the dose of THF or solvents evaporation time both could decrease the surface pore size of the membrane, causing the increase of SA rejection ratio. But it was worth noting that too much THF and too long solvent evaporation time reduced the membrane flux. Therefore, based on the performances of the membrane including hydrophilicity, flux performance, SA rejection ratio, the surface roughness, and the flux recovery ratio, the blended membrane prepared under the THF/NMP mixing ratio of $1: 9$ with solvent evaporation for $60 \mathrm{~s}$ showed optimal performance.

\section{Conflicts of interest}

The authors declare no conflict of interest.

\section{Acknowledgements}

This work was supported by the National Natural Science Foundation of China (51678377), the State Key Laboratory of Separation Membranes and Membrane Processes (Tianjin Polytechnic University) (M2-201809), and the Fundamental Research Funds for the Central Universities. We thank Yi He at Analytical \& Testing Center, Sichuan University for his kind help with SEM measurements. The views and ideas expressed herein are solely those of the authors and do not represent the ideas of the funding agencies in any form.

\section{References}

1 J. Xu and Z.-L. Xu, J. Membr. Sci., 2002, 208, 203-212.

2 X. Fan, Y. Su, X. Zhao, Y. Li, R. Zhang, J. Zhao, Z. Jiang, J. Zhu, Y. Ma and Y. Liu, J. Membr. Sci., 2014, 464, 100-109.

3 L.-F. Fang, B.-K. Zhu, L.-P. Zhu, H. Matsuyama and S. Zhao, J. Membr. Sci., 2017, 524, 235-244.

4 B. Liu, C. Chen, W. Zhang, J. Crittenden and Y. Chen, Desalination, 2012, 307, 26-33.

5 W.-d. Liu, Y.-h. Zhang, L.-f. Fang, B.-k. Zhu and L.-p. Zhu, Chin. J. Polym. Sci., 2012, 30, 568-577.

6 Y. Zhang, X. Tong, B. Zhang, C. Zhang, H. Zhang and Y. Chen, J. Membr. Sci., 2018, 548, 32-41.

7 Z. Zhou, S. Rajabzadeh, A. R. Shaikh, Y. Kakihana, W. Ma and H. Matsuyama, J. Membr. Sci., 2016, 514, 537-546.

8 I. Soroko, M. P. Lopes and A. Livingston, J. Membr. Sci., 2011, 381, 152-162.

9 A. K. Hołda, B. Aernouts, W. Saeys and I. F. J. Vankelecom, J. Membr. Sci., 2013, 442, 196-205.

10 I. Soroko, M. Makowski, F. Spill and A. Livingston, J. Membr. Sci., 2011, 381, 163-171.

11 H. Rabiee, M. H. D. A. Farahani and V. Vatanpour, J. Membr. Sci., 2014, 472, 185-193.

12 K. J. Roy, T. V. Anjali and A. Sujith, J. Mater. Sci., 2017, 52, 5708-5725.

13 H. Zhang, X. Hu, Y. Chen, B. Cheng, D. Liu and Y. Zhang, J. Mater. Sci., 2015, 50, 4371-4378.

14 W. Qiu, L. Liu and W. J. Koros, J. Membr. Sci., 2017, 529, 150158.

15 P. Vandezande, X. Li, L. E. M. Gevers and I. F. J. Vankelecom, J. Membr. Sci., 2009, 330, 307-318.

16 S. P. Nunes, R. Sougrat, B. Hooghan, D. H. Anjum, A. R. Behzad, L. Zhao, N. Pradeep, I. Pinnau, U. Vainio and K.-V. Peinemann, Macromolecules, 2010, 43, 8079-8085.

17 K.-V. Peinemann, V. Abetz and P. F. W. Simon, Nat. Mater., 2007, 6, 992-996.

18 H. Wu, T. Li, B. Liu, C. Chen, S. Wang and J. C. Crittenden, Appl. Surf. Sci., 2018, 455, 987-996.

19 W. Xie, T. Li, C. Chen, H. Wu, S. Liang, H. Chang, B. Liu, E. Drioli, Q. Wang and J. C. Crittenden, Ind. Eng. Chem. Res., 2019, 58(16), 6413-6423.

20 S. H. Ahn, J. A. Seo, J. H. Kim, Y. Ko and S. U. Hong, J. Membr. Sci., 2009, 345, 128-133.

21 B. Liu, C. Chen, T. Li, J. Crittenden and Y. Chen, J. Membr. Sci., 2013, 445, 66-75.

22 K. Katsoufidou, S. G. Yiantsios and A. J. Karabelas, Desalination, 2008, 220, 214-227.

23 Y. Ye, P. L. Clech, V. Chen and A. G. Fane, J. Membr. Sci., 2005, 264, 190-199.

24 Y. Ye, p. L. Clech, V. Chen, A. G. Fane and B. Jefferson, Desalination, 2005, 175, 7-20.

25 J.-F. Li, Z.-L. Xu, H. Yang, L.-Y. Yu and M. Liu, Appl. Surf. Sci., 2009, 255, 4725-4732. 
26 X. Zhao, Y. Su, W. Chen, J. Peng and Z. Jiang, J. Membr. Sci., 2012, 415-416, 824-834.

27 X. Zhao, Y. Su, Y. Li, R. Zhang, J. Zhao and Z. Jiang, J. Membr. Sci., 2014, 450, 111-123.

28 G. Rong, D. Zhou, X. Han and J. Pang, Appl. Surf. Sci., 2018, 427, 1065-1075.

29 C. M. Hansen, Hansen solubility parameters: a users hand book, CRC Press, Taylor \& Francis Group, Florida, 2nd edn, 2007.

30 R. Guan, H. Dai, C. Li, J. Liu and J. Xu, J. Membr. Sci., 2006, 277, 148-156.

31 M. Mulder, Basic Principles of Membrane Technology, Kluwer Academic Publishers, 2rd edn, 1996.

32 E. Bagheripour, A. R. Moghadassi and S. M. Hosseini, Arabian J. Chem., 2017, 10, S3375-S3380.

33 J. Brandrup and E. H. Immergut, Polymer handbook, Wiley, New York, 3rd edn, 1989.

34 N. A. Hashim, F. Liu and K. Li, J. Membr. Sci., 2009, 345, 134141.
35 R. Patel, M. Patel, S. H. Ahn, Y. K. Sung, H.-K. Lee, J. H. Kim and J.-S. Sung, Mater. Sci. Eng., C, 2013, 33, 1662-1670.

36 X. Ma, Y. Su, Q. Sun, Y. Wang and Z. Jiang, J. Membr. Sci., 2007, 292, 116-124.

37 C. Chen, L. Tang, B. Liu, X. Zhang, J. Crittenden, K. L. Chen and Y. Chen, J. Membr. Sci., 2015, 487, 1-11.

38 Y. Gu, R. M. Dorin and U. Wiesner, Nano Lett., 2013, 13, 5323-5328.

39 H. Guo and M. Ulbricht, J. Membr. Sci., 2011, 372, 331-339.

40 Q. Zhang, J. Jiang, F. Gao, G. Zhang, X. Zhan and F. Chen, Chem. Eng. J., 2017, 321, 412-423.

41 X. Fu, T. Maruyama, T. Sotani and H. Matsuyama, J. Membr. Sci., 2008, 320, 483-491.

42 S. H. Woo, J. Park and B. R. Min, Sep. Purif. Technol., 2015, 146, 187-191.

43 Z. Xu, J. Liao, H. Tang and N. Li, J. Membr. Sci., 2018, 548, 481-489. 